\title{
NACIMIENTO EN EL SAHARA OCCIDENTAL DURANTE LA ETAPA COLONIAL Y CUESTIONES DE NACIONALIDAD (STS 207/2020 DE 29 DE MAYO. SALA DE LO CIVIL. PLENO)
}

\author{
BIRTH IN THE WESTERN SAHARA DURING THE COLONIAL \\ PERIOD AND NATIONALITY ISSUES (JUDGMENT OF THE \\ SUPREME COURT 207/2020, MAY 29. PLENARY CIVIL SECTION)
}

\author{
Marina Vargas Gómez-UrRutia \\ Profesora Titular de Derecho internacional privado \\ Universidad Nacional de Educación a Distancia (UNED) \\ ORCID ID: 0000-0002-4574-341X
}

Recibido: 16.11.2020 / Aceptado: 14.12.2020

DOI: https://doi.org/10.20318/cdt.2021.6021

\begin{abstract}
Resumen: Nacer en España o nacer en territorio español a los efectos de aplicación del artículo 17.1 c) del Código civil tiene trascendencia jurídica si el interesado nació en la ex colonia del Sahara antes del 26 de febrero de 1976, fecha en que España abandonara aquel territorio. La sentencia 207/2020, de 29 de mayo del Pleno de la Sala de lo Civil del Tribunal Supremo aborda, no sin ciertas dudas y con un Voto particular, la cuestión acerca de qué nacionalidad tenían los naturales del Sahara antes y después de la Ley 40/1975. Tomando la doctrina de la Sala $3^{\text {a }}$ TS en relación con la consideración de apátridas de algunos saharauis y confirmando la postura de la DGRN sobre las consecuencias del no ejercicio del derecho de opción conforme al RD 2258/76, el Pleno de la Sala de lo Civil ha perdido una excelente oportunidad de declarar la inconstitucionalidad sobrevenida del citado RD de 1976. ¿Qué razones justifican el fallo? ¿Qué otros argumentos hubieran podido esgrimirse? Con este enfoque se aborda nuestro comentario.

Palabras clave: nacionalidad española de los saharauis y art. $17.1 \mathrm{c}$ ) C.c; ius soli y nacimiento en España; la noción política de territorio español y privación de la nacionalidad a los naturales de la provincia del Sahara.
\end{abstract}

Abstract: Being born in Spain or being born in the Spanish territory for the purposes of the application of article $17.1 \mathrm{c}$ ) of the Civil Code has legal significance if the person concerned was born in the former colony of the Sahara before February 26, 1976, the date on which Spain left that territory. The Judgment 207/2020 of 29 May of the Plenary of the Civil Chamber of the Supreme Court addresses, not without certain doubts and with an individual vote, the question of what nationality the natives of the Sahara had before and after Law 40/1975. Taking the doctrine of the 3rd SC in relation to the consideration of statelessness of some Saharans and confirming the position of the DGRN on the consequences of not exercising the right of option under RD 2258/76, the Plenary of the Civil Chamber has lost an excellent opportunity to declare the unconstitutionality of that RD of 1976 . What reasons justify the ruling? What other arguments could have been used? This approach addresses our commentary.

Keywords: Spanish nationality of the Saharawis and Article $17.1 \mathrm{c}$ ) Civil Code; ius soli and birth in Spain; the political notion of Spanish territory and deprivation of nationality to the natives of the province of the Sahara. 
Sumario: I. Resumen de los antecedentes y pretensiones de la demandante. II. Los elementos de la discusión jurídica: el RD 2258/1976 y la prolongación de sus efectos en el tiempo a los saharauis. 1. De la vinculación del territorio saharaui a España: elementos para una comprensión jurídico-política de este territorio colonial y su proyección sobre las normas de atribución iure soli de la nacionalidad española a los saharauis. 2. Posibilidad de una interpretación evolutiva, actual y constitucional del RD 2258/1976: su inaplicabilidad al supuesto de la STS 107/2020.

\section{Resumen de los antecedentes y pretensiones de la demandante}

1. La STS 207/2020 de 29 de mayo $^{1}$ resuelve un recurso extraordinario de infracción procesal y un recurso de casación interpuesto por la Dirección General de los Registros y del Notariado (hoy Dirección General de Seguridad Jurídica y Fe Pública) contra la sentencia dictada el 27 de mayo de 2017 por la Sección $3^{\text {a }}$ de la Audiencia Provincial de Illes Balears en recurso de apelación dimanante de las actuaciones de juicio ordinario ante el Juzgado de $1^{\mathrm{a}}$ Instancia núm. 14 de Palma de Mallorca, sobre nacionalidad.

2. La demandante, de origen saharaui y nacida en el Sahara Occidental en 1973 (es decir, antes del RD 2258/1976), entendía que le correspondía la nacionalidad española de origen por ser hija de españoles naturales también del Sahara Occidental y así lo solicitó ante el Registro civil de su domicilio (en Ibiza). El Encargado del Registro civil rechazó la petición. A partir de esta desestimación se inicia la vía judicial en demanda de nacionalidad ante los juzgados de primera instancia competentes, pleito que finaliza en casación ante el Tribunal Supremo (en adelante, TS). En la sentencia de primera instancia la magistrada-juez desestimó la demanda de nacionalidad pues la solicitante no probaba ser hija de españoles (criterio del ius sanguinis), si bien valoró que sí sería aplicable a la demandante el art. 17.1.c) C. civil ${ }^{2}$. Recurrida la sentencia en apelación, la Audiencia Provincial de Illes Balears estimó el recurso declarando el derecho de la demandante a la nacionalidad española de origen desde la fecha de su nacimiento, ordenando la inscripción en el Registro civil ${ }^{3}$. Como era de esperar, la DGRN se alzó ante el Tribunal Supremo articulando dos recursos con un único motivo cada uno: el extraordinario de revisión por infracción procesal y el recurso de casación ${ }^{4}$. En su Fallo, el Supremo desestimó el primero, pero admitió el segundo casando la sentencia recurrida y ordenando a la Audiencia Provincial de Illes Balears la desestimación de la demanda de nacionalidad ${ }^{5}$.

\footnotetext{
${ }^{1}$ Tribunal Supremo. Sala de lo Civil. Pleno. Sentencia 207/2020, de 29 de mayo. ECLI: ES:TS:2020:1240.

${ }^{2}$ Indicaba así la vía "apropiada" con sustento en la jurisprudencia de la Audiencia Nacional sobre la situación de apátridas de los saharauis (SJPI núm. 14 de Palma de Mallorca, de 2 de diciembre de 2016). La pretensión de la demandante se desestimó acogiéndose la tesis sostenida por la DGRN y el Juez Encargado del RC según la cual: "los nacidos en el territorio del Sáhara cuando este era posesión española no eran propiamente nacionales españoles, sino sólo súbditos de España que se beneficiaban de la nacionalidad española". Sobre esta base, el Centro Directivo en la oposición a la demanda de nacionalidad recordaba, entre otros, que el RD 2258/1976, de 10 de agosto (BOE 20/11/1975), sobre opción de la nacionalidad española por parte de los naturales del Sahara, les permitió optar por la nacionalidad española en el plazo de un año (efectos de la opción: hasta el 29/9/1977).

${ }^{3}$ SAP Illes Balears de 26 de mayo de 2017. La sala hace una corrección de la sentencia de primera instancia y, aplicando el principio iura novit curia, estima la demanda con fundamento en el art. 17.1 c) C.c. Aunque el Ministerio Fiscal se opuso en un primer momento, en el acto del juicio interesó su estimación de la demanda con fundamento en dicho precepto: "Son españoles de origen: c) Los nacidos en España de padres extranjeros, si ambos carecieren de nacionalidad o si la legislación de ninguno de ellos atribuye al hijo una nacionalidad". La cuestión de la apatridia de los saharauis en perspectiva histórica y la evolución de la jurisprudencia española para el reconocimiento del estatuto de apátrida de los saharauis no es objeto de este comentario, aunque no tenemos la menor duda de que ha condicionado la respuesta mayoritaria del Pleno de la Sala. En particular, merece atención el extenso trabajo de M.J. LóPEz BARONI, “Apátridas saharauis en España: Europa y su memoria”, Anuario Mexicano de Derecho Internacional, vol. XIV, 2014, pp. 381-433, donde analiza la amplia casuística de la jurisprudencia española ante los casos particulares planteados.

${ }^{4}$ Mientras que el motivo de la infracción procesal lo fue por incongruencia extra petita (art. 218.1 LEC y art. 24 CE) el motivo de la casación lo fue por infracción del art. 17.1 c) C.c en la interpretación dada al mismo por la Sala Primera del Tribunal Supremo en sentencia del Pleno de 28 de octubre de 1988 ( $n^{\circ}$ 617/1996).

${ }^{5}$ El Pleno examina el motivo alegado por la DGRN que se centra básicamente en dos ideas: (i) la doctrina de la Sala $1^{\mathrm{a}}$ sobre la consideración del territorio español del Sahara occidental como territorio que "no forma parte del territorio nacional" y la tesis de la provincialización del territorio colonial (territorio no autónomo del Sahara) con similitudes en su administración
} 
3. Voto Particular. La magistrada $D^{\mathrm{a}} \mathrm{M}^{\mathrm{a}}$ Ángeles Parra Lucán redacta el Voto particular, con adhesión de dos magistrados más 6 . Este Voto expresa la discrepancia respetuosa frente a la opinión mayoritaria de la Sala, proponiendo otra interpretación, igualmente ajustada a Derecho, aunque recalca que la misma supondría "una innovación jurisprudencial". En este sentido argumenta con sólido fundamento las razones que hubieran permitido estimar la demanda y declarar la nacionalidad española de la solicitante. La estructura del Voto particular se articula en torno a dos órdenes de consideraciones jurídicas:

(1) las razones invocadas por la demandante: aplicabilidad del art. 17 del Código civil, en la redacción vigente en 1973, año de nacimiento de la solicitante, y la no aplicabilidad en el tiempo del RD 2258/1976 por contravenir sus efectos (privación de la nacionalidad) lo dispuesto en el artículo 11.2 CE (con argumentos que arrojan luz para el entendimiento de su inconstitucionalidad sobrevenida); $y$,

(2) los fundamentos de la sentencia recurrida: no infracción de la doctrina de la Sala $1^{\mathrm{a}} \mathrm{TS}$ en interpretación del art. $17.1 \mathrm{c}$ ) del C. civil y apoyo en la doctrina de la Sala $3^{\mathrm{a}}$ TS que, con fundamento en numerosas sentencias de tribunales inferiores, ha corregido al Ministerio de Justicia en el sentido de que el Sahara Occidental forma parte del territorio español a los efectos del vigente art. 22.2 a) Cc (nacimiento en España y adquisición por residencia de un año).

4. Este Voto particular revela la trascendencia jurídica de la cuestión debatida ante el Pleno de la Sala Primera, cuyos elementos examinaremos en las próximas líneas en torno a dos postulados: (i) aplicabilidad de las normas de atribución iure soli de la nacionalidad española a los nacidos en el Sahara antes de 1976. Tomaremos como elemento de reflexión la discusión teórica sobre la vinculación del territorio saharaui a España y la respuesta de la Sala $3^{\text {a }}$ del Tribunal Supremo en aplicación de la adquisición por residencia del nacido en España; y (ii) una interpretación actual y constitucional del RD 2258/1976 que impida su aplicación por el Ministerio de Justicia (DGRN) cuando produzca como resultado la privación de la nacionalidad española a los nacidos en el Sahara occidental antes de la descolonización en las circunstancias como las concurrentes en la solicitante. Tomaremos como elemento de reflexión los derechos políticos reconocidos a los saharauis durante la etapa de "provincialización" y el reconocimiento documental de su vinculación a España mediante documentos de identidad españoles y como elemento de contraste la no aplicación del mencionado RD si diera como resultado de la privación de la nacionalidad española.

II. Los elementos de la discusión jurídica: el RD 2258/1976 y la prolongación en el tiempo de sus efectos sobre las normas de atribución iure soli y de privación de la nacionalidad española a los saharauis

\section{De la vinculación del territorio saharaui a España: elementos para una comprensión jurídico- política y su proyección sobre las normas de atribución iure soli de la nacionalidad española a los saharauis.}

5. Recordemos que la solicitante había nacido en 1973 en el territorio del Sahara Occidental y que sus progenitores también habían nacido en dicho territorio. La primera pregunta directa consiste en saber si tenía o no la nacionalidad española. Es sabido que para la determinación de si una persona es o fue español ha de estarse a las normas sobre nacionalidad vigentes en el momento de su nacimiento

al de la provincia "y que nunca ha formado parte del territorio nacional" (Ley 40/1975, de 19 de noviembre, sobre descolonización del Shara); y (ii) como consecuencia lógica de lo anterior, la no aplicación a la solicitante del criterio del ius soli en los términos del art. $17.1 \mathrm{c}$ ) C. civil).

${ }^{6}$ Que formula la magistrada Sra. Da Mángeles Parra Lucán, y al que se adhieren los magistrados Sres. D. Antonio Salas Carceller y D. Rafael Sarazá Jimena. 
tanto las propias como las de los progenitores ${ }^{7}$. La solicitante, en el expediente gubernativo promovido en 2009, solicitó la nacionalidad española por aplicación de la doctrina relativa a la consolidación de la nacionalidad española en los términos de la STS de 28 de octubre de $1998^{8}$.

6. Denegada la petición por no concurrir en la solicitante los requisitos de la citada doctrina del alto tribunal, en concreto, no haber ejercido el derecho de opción en los términos establecidos en el RD 2258/1976, de 10 de agosto, la solicitante recurre ante la DGRN que resuelve en igual sentido desestimatorio con apoyo en su propia doctrina sobre el no reconocimiento de la nacionalidad española a los nacidos en el territorio del Sahara cuando este era posesión española. Por su relevancia en la discusión doctrinal, se reproduce el argumento de la DGRN:

(i) que «los nacidos en el territorio del Sahara cuando este era posesión española no eran propiamente nacionales españoles, sino sólo súbditos de España que se beneficiaban de la nacionalidad española», lo que explicaba que se les permitiera optar por la nacionalidad española en el plazo de un año a partir de la entrada en vigor del RD 2258/1976; (ii) que esto era debido a que, pese a tratarse de un tema controvertido (pues se llegó a considerar provincia española), el territorio del Sahara Occidental no formó parte del territorio nacional; y (iii) que no era aplicable la sentencia de esta sala de 28 de octubre de 1998 porque «en este caso la interesada no ha acreditado que cuando estuvo en vigor el real decreto de 1976 sus representantes legales -dada su minoría de edad en aquel momento- estuviesen imposibilitados de facto para optar a la nacionalidad española por haber permanecido en los territorios ocupados; antes al contrario, manifiesta que abandonaron dichos territorios en dirección a los campamentos de refugiados saharauis», y porque «no consta el título inscrito en el Registro Civil y no está probada la posesión de la nacionalidad española en los términos y duración que establece el artículo $18 \mathrm{CC}$, siendo incluso la recurrente titular de un pasaporte argelino».

7. El "tema controvertido" a que hace referencia la DGRN puede examinarse desde varias perspectivas. Desde un punto de vista jurídico, el cambio de fórmula se sitúa en la reforma operada por la Ley de 15 de julio de 1954 que sustituye la anterior "nacidos en territorio español" por "nacidos en España". Así lo hace S. TALEBBUIA HASSAN al preguntarse sobre el propósito de este cambio9.

8. Pero una perspectiva internacional es necesaria si queremos sostener, como hacemos, que el cambio de fórmula no fue casual. Compartimos el análisis J. SOROETA en torno a la comprensión de este extremo a la luz de la "cuestión española" y la negativa de las Naciones Unidas a admitir su ingreso en la Organización. Uno de los muchos obstáculos residía en el proceso de descolonización ya iniciado. Lejos de seguir los pasos de otras ex potencias coloniales, España hizo caso omiso al requerimiento de la Asamblea General para comunicar el tipo de medidas a adoptar para promover y preparar a la po-

\footnotetext{
${ }^{7}$ Conviene recordar que la primera gran reforma sobre nacionalidad es operada por Ley de 15 de julio de 1954, vigente en el momento del nacimiento de la solicitante y aplicable de acuerdo con lo dispuesto en la Disposición Transitoria primera de la Ley 18/1990 de 17 de diciembre: La adquisición o la pérdida de la nacionalidad española, conforme a la legislación anterior, mantienen su efecto, aunque la causa de adquisición o de pérdida no esté prevista en la ley actual. Por todos, A. ÁLVAREZ Rodríguez, Nociones básicas de Registro Civil y problemas frecuentes en materia de nacionalidad, Ediciones GPS, Servicios a la Ciudadanía de CCOO, 2015.

${ }^{8}$ ¿Estaba en la mens legislatoris de 1954 pretender una distinción jurídico-política del territorio en función de dónde se había producido el nacimiento o se trata de una cuestión de estilo? El argumento para sostener que la diferencia es mera cuestión de estilo, con base en la propia sentencia de la Sala Primera que utiliza indistintamente ambas fórmulas, solo es asumible con una mirada que no tome en cuenta los intereses internacionales de la España en 1954. La Dictadura necesitaba un urgente "reconocimiento" internacional si quería recibir ayuda económica de los Estados Unidos, las negociaciones para ingreso de España en las Naciones Unidas (la "cuestión española") llevaban encalladas más de diez años y, finalmente, el ingreso en las Naciones Unidas se condicionaba al cumplimiento de las resoluciones de la Asamblea sobre los procesos de descolonización en África.

${ }^{9}$ S. TAlebbuia Hassan, "Nacionalidad española de los saharauis: comentario a la sentencia del Tribunal Supremo 207/2020", en Abogacía Española. Consejo General. Blog Actualidad y Opinión. Disponible en: https://www.abogacia.es/actualidad/opinion-y-analisis/nacionalidad-espanola-de-los-saharauis-comentario-a-la-sentencia-del-tribunal-supremo-207-2020/.
} 
blación saharaui para que en su día pudiera ejercer el derecho de autodeterminación. España dictó en 1958 el Decreto de Provincialización ${ }^{10}$ que pretendía asimilar el territorio colonial saharaui al territorio metropolitano, "algo expresamente prohibido por el Derecho Internacional" recordando que en materia de nacionalidad los Estados son soberanos para el establecimiento de sus requisitos sobre "su territorio nacional", el gobierno de Franco trató de asimilar a la población saharaui a la española proporcionándoles el acceso a la función pública (podían ser funcionarios del Estado) condición que entonces solo estaba reservada a los nacionales españoles. Igualmente, tenían DNI y pasaporte españoles ${ }^{12}$.

9. En este sentido, no es aventurado afirmar que para el legislador de 1954 el cambio de la fórmula convenía política e internacionalmente al régimen si con ello se allanaba el camino hacia el ingreso de España en las Naciones Unidas negado durante más de diez años ${ }^{13}$. Ello no empecé a que España pudiera dar a la población saharaui todo tipo de facilidades para que pudieran ostentarse como españoles. No es irrelevante la comprensión de estos hechos ni fácil ordenar la errática administración del territorio saharaui bajo la tutela de España en una época en que la tesis de la provincialización/asimilación de sus habitantes quedó asentada para posteriormente, en 1975, ser negada en la Ley 40/1975 y su norma de desarrollo, el RD 2258/1976.

10. Compartimos los argumentos del Voto particular cuando, en el examen de las alegaciones de la demandante, acoge sus propios fundamentos (FD segundo): "era hija de españoles" y, en este sentido, no podía ser privada de esta nacionalidad dado que el RD 2258/1976 no le era de aplicación. Repara el Voto particular con acierto en la diferencia (esencial de Derecho internacional) del territorio colonial como espacio diferenciado del propiamente nacional y la "asimilación" colectiva e independiente de la voluntad de sus habitantes. La Carta de las Naciones Unidas no declara que sea contrario a los intereses de los pueblos de los territorios de las excolonias que pueda la potencia colonizadora dictar normas "de asimilación". Mas, lo que no permite el Derecho internacional es privar a los habitantes de esos territorios de los derechos reconocidos individualmente: El Voto particular insiste en que el RD 2258/1976 provoca como efecto la desposesión de la nacionalidad española a los habitantes del territorio del Sahara.

11. Sin embargo, el Pleno de la Sala se cuida de no censurar esta norma. En su FJ Sexto, numeral $5^{\circ}$, señala que:

“..., en consecuencia, cualquiera que sea la opinión que merezca esta normativa específica y cualquiera que sea la opinión sobre la actuación de España como potencia colonizadora a lo largo de toda su presencia en el Sahara Occidental, lo indiscutible es que se reconoce la condición colonial del Sahara y que por tanto no puede ser considera España a los efectos de la nacionalidad de origen contemplada en el art. 17.1 c) CC". En otras palabras, apostilla el TS, "no son nacidos en España quienes nacieron en un territorio durante la etapa en que fue colonia española". Fundamenta esta interpretación con apoyo en dos sentencias de la Sala $3^{\text {a }}$ del mismo Tribunal sobre reconocimiento del estatuto de apátridas a las personas nacidas en el Sahara Occidental antes de la descolonización y cuyas circunstancias son similares a las de la demandante”.

${ }^{10}$ J. Soroeta Liceras, "Marco jurídico político de la cuestión del Sahara Occidental", en Universidad y Sahara occidental. Reflexiones para la solución de un conflicto (P. Martínez Lillo, S. Arias Careaga,

C. Tanarro Alonso, J. Weingärtner, Coords.), Colección Cuadernos Solidarios No 6, Universidad Autónoma de Madrid, 2007, pp. 35-52.

${ }^{11}$ Como explica J. Soroeta, op. cit, p. 36, (...) "la Resolución 2625 (XXV) de la Asamblea General de la ONU estableció claramente que la condición jurídica de un territorio colonial es distinta y separada de la condición jurídica del territorio metropolitano. En consecuencia, el ordenamiento internacional prohíbe que la potencia colonial asimile a la población y el territorio de la colonia a su propio territorio y a su propia población".

${ }^{12}$ La consulta de esta normativa se encuentra sistematizada por la profesora Aurelia Álvarez Rodríguez en su Blog migrar con derechos. Disponible en: http://www.migrarconderechos.es/search/resultadosE/?allSearchField=sAHARA\&pageSize=8

${ }^{13} \mathrm{El}$ ingreso se produjo el 14 de diciembre de 1955. Sobre la "cuestión española" (negativa de la ONU al ingreso de España en la organización) son numerosos los estudios. Baste la referencia a un clásico entre nosotros, la obra colectiva $O N U$ año $X X$, 1946-1966, Madrid, Tecnos, 1966. De entre sus colaboraciones, destaco la del profesor F. Murillo Ferrol, "La Organización de las Naciones Unidas y la opinión española”, pp. 95-108. 
12. El reconocimiento del estatuto de apátrida a saharauis por parte de la Sala $3^{\mathrm{a}}$ del Tribunal Supremo no es cuestión inocua, por las razones que veremos a continuación. Por una parte, las Audiencias Provinciales son proclives a sustentar sus decisiones de reconocimiento de la nacionalidad española de los saharauis por posesión de estado (art. $18 \mathrm{Cc}$ ) argumentando, entre otras, el interés en evitar situaciones de apatridia ${ }^{14}$. La Audiencia Nacional en el examen de las solicitudes de concesión del estatuto de apátrida niegan su reconocimiento, endureciendo la carga de la prueba al exigir que se demuestre haber solicitado la nacionalidad de un determinado Estado (Argelia o Marruecos, por ejemplo) y que esta se ha denegado. La incómoda interpretación del RD 2258/1976 se ha soslayado. Pero en el Supremo la situación ha cambiado. Como ha señalado LóPEZ BARONI (...) “al conceder la apatridia a los saharauis, el Tribunal Supremo español ha tratado de reparar mediante mecanismos jurídicos un conflicto de naturaleza política" (...) pero paradójicamente "posibilita a los nacidos en el Sahara Occidental antes de 1975 solicitar la nacionalidad española, dado que tanto la normativa nacional como la internacional tratan de limitar o restringir la existencia de apátridas" ${ }^{\prime 15}$.

13. Tarde o temprano llegaría al TS la cuestión de la atribución de la nacionalidad en sede del art. 17.1 c) C.c, como sucede en el asunto objeto de este comentario. Y es justamente en esta sede donde se (debería) (re)abrir el debate sobre la posible la inconstitucionalidad de los efectos del RD 2258/1976 sobre la prolongación en el tiempo de los resultados de esta norma y su posible inconstitucional si trae como consecuencia el mantenimiento de la situación de apatridia de la persona concernida.

14. La Sala $1^{\mathrm{a}}$ afirma que su interpretación es "armónica" con la jurisprudencia de la Sala $3^{\mathrm{a}}$ a partir de las sentencias de 20 de noviembre de 2007 y 18 de julio de 2008. Conviene constatar si esta referencia a "situaciones similares" a las del litigio que nos ocupa es o no adecuada; pues, "similar" no es identidad de causa ni de petitum. En la STS de 20 de noviembre de $2007^{16}$ el litigio se plantea contra la Administración General del Estado para el reconocimiento del estatuto de apátrida que fue desestimado por la Audiencia Nacional. En la especie, la demandante asumió ab initio su condición de apátrida por lo que la causa petitum no fue la aplicación a la demandante de las previsiones sobre atribución de la nacionalidad española de origen al amparo del art. 17 1. apartados a) y d) del C. civil. Sí es cierto que nuestra sentencia hace un examen minucioso y extenso de la jurisprudencia previa; en concreto, toma las consideraciones de la STS 28 de octubre de $1998^{17}$ y las extrapola al caso en la especie para fundamentar la imposibilidad de la demandante de cumplir las condiciones del RD 2258/1976 ${ }^{18}$.

\footnotetext{
${ }^{14}$ Véase el estudio de A. Ortega Giménez, "Nacionalidad española de los habitantes del Sahara Occidental. Comentario a la Sentencia de la Audiencia Provincial de Barcelona, de 11 de noviembre de 2019", Cuadernos de Derecho Transnacional (Octubre 2020), Vol. 12, No 2, pp. 1110-1118.

${ }^{15}$ M.J. LÓPEZ BARONI, “Apátridas saharauis en España: Europa y su memoria”, op. cit., p. 416 y 428.

${ }^{16}$ STS 8948/2007 - ECLI: ES:TS:2007:8948.

${ }^{17}$ STS 6268/1998 - ECLI: ES:TS:1998:6268. Como es sabido, en esta sentencia el Tribunal Supremo falla a favor del demandante declarando la nacionalidad española por posesión de Estado

${ }^{18} \mathrm{Sin}$ embargo, en la mencionada sentencia también declara que "si el territorio de marras, calificado como español, fue luego considerado no español, (...) ello no significa que al amparo de la calificación, bajo la que se desarrollaron o tuvieron ocurrencia los hechos determinantes del título, no se produjera una apariencia legitimadora, pese a la anulación posterior de la razón jurídica sustentadora. Como afirma la doctrina, "si se llega a demostrar que quien estaba beneficiándose de la nacionalidad española "iure sanguinis o iure soli", no era, en realidad español" (en este caso supondría que no tenía la plena nacionalidad), al ser nulo el título de atribución respectivo, no parece justo que la eficacia retroactiva de la nulidad, (recogida "expresis verbis" en la Ley descolonizadora,) se lleve a sus últimas consecuencias en materia de nacionalidad" (FJ $8^{\circ}$ ). Recogiendo, así la tesis de la asimilación completa. Son múltiples los comentarios doctrinales a esta importante sentencia, así como a la dictada un año después por la Sala Tercera del Tribunal Supremo (STS del 7 noviembre 1999). Entre otros: M. GuZMÁn ZAPATER, "Descolonización y nacionalidad. el caso saharaui. Consolidación de nacionalidad”, Cuadernos Civitas de Jurisprudencia civil, № 52, 2000, pp. 15-28. C. Ruiz Miguel, "Nacionalidad española de los ciudadanos saharauis: secuela de una descolonización frustrada (y frustrante)", Revista General de Derecho Administrativo, № 663, 1999, pp. 14235-14246; J. Soroeta Liceras, "La problemática de la nacionalidad de los habitantes de los territorios dependientes y el caso del Sahara Occidental, Anuario español de Derecho internacional, vol. XV, 1999, pp. 167-202. En particular, merece atención el extenso trabajo de M.J. LóPEZ BARONI, “Apátridas saharauis en España: Europa y su memoria”, Anuario Mexicano de Derecho Internacional, vol. XIV, 2014, pp. 381-433, donde analiza la amplia casuística de la jurisprudencia española ante los casos particulares planteados. En relación con las dos sentencias del Tribunal Supremo de 1998 y de 1999, al analizar la naturaleza del territorio y de la población del Sahara, muestran
} 
15. En la STS de 18 de julio de $2008^{19}$ se plantea nuevamente un reconocimiento del estatuto de apátrida de una ciudadana saharaui. La referencia a la cuestión de la nacionalidad marroquí de la solicitante la plantea el Ministerio de Interior para negarle el estatuto de apátrida. Esta sentencia es un ejemplo claro de lo que hemos afirmado anteriormente. Y es que la Audiencia Nacional endurece la carga de la prueba y toma en cuenta un Dictamen del Tribunal de Justicia internacional para justificar "la no vinculación del territorio del Sahara Occidental con Marruecos" (FJ $8^{\circ}$ ) y la situación de los saharauis en los campamentos de Tinduff, al suroeste de Argelia país que los documenta por razones humanitarias con documentos de viaje para poder salir de su territorio (en concreto, del desierto cercano) por vía aérea (FJ $9^{\circ}$ ). Tampoco existe en esta sentencia un examen de la nacionalidad española de la solicitante del estatuto de apátrida ni referencia alguna al RD 2258/1976. En consecuencia, no existe similitud con el asunto del litigio, salvo la condición de saharaui de las demandantes.

16. Quizá sea plausible pensar que el Pleno de la Sala $1^{a}$, con 6 votos a favor de sus 9 integrantes, haya descartado hacer ese giro "interpretativo innovador" que postulaban 3 de sus miembros en el Voto particular. Acaso el Pleno de la Sala $1^{a}$ haya decidido mantener la aplicación del RD 2258/1976 en sus términos dejando al margen la posible inconstitucionalidad de sus efectos por mor de la aplicación en el tiempo de la citada norma (desposesión de la nacionalidad española). Somos conscientes de que nuestro alto tribunal ha conseguido reparar en varias de sus sentencias la inacción del legislador ${ }^{20}$ ante un conflicto de clara naturaleza política. Conceder el estatuto de apátrida es lo que más se acerca, en cuanto a sus beneficios, a la condición de nacional español. Pero no es suficiente. En el momento en que se escriben estas líneas nos preocupan las noticias sobre la reactivación del conflicto entre el Frente Polisario y el Reino de Marruecos por la ruptura unilateral del alto el fuego por la parte marroquí. Entonces, ¿qué tendría que suceder para que el Congreso de los Diputados se decida a abordar, en una norma ad hoc, la cuestión de la nacionalidad española de los saharauis? ${ }^{21}$.

\section{Posibilidad de una interpretación evolutiva, actual y constitucional del RD 2258/1976: su inapli- cabilidad al supuesto de la STS 107/2020}

17. La Ley 40/1976 de 19 de noviembre sobre descolonización del Sahara habilitó la promulgación del RD 2258/1976, de 10 de agosto que otorgaba un derecho de opción a los naturales del Sahara

evidentes contracciones pues mientras que la de la Sala Primera (1998) asume la tesis de la asimilación completa al margen del Derecho internacional, la de la Sala Tercera (1999) acoge la opinión del Consejo de Estado en sus dictámenes sobre Guinea Ecuatorial e Ifni (que a su vez inspiraron la Ley de Descolonización del Sáhara de 1975), esto es, "que las colonias africanas nunca formaron parte de España".

${ }^{19}$ STS 4083/2008 - ECLI: ES:TS:2008:4083.

${ }^{20}$ En la Proposición no de Ley presentada el 11/09/2012 por el Grupo Parlamentario de IU, ICV-EUiA, CHA, sobre denuncia de los “Acuerdos de Madrid” y del Decreto RD2258/76 y otras medidas sobre el Sahara Occidental, se instaba a al Gobierno a denunciar los citados acuerdos y decreto por procedimiento de urgencia; a la restitución inmediata de la nacionalidad española a todos los saharauis censados en 1974 y sus descendientes, y así mismo, los que puedan demostrar, con la aportación de las documentaciones correspondientes, su derecho a mantener $\mathrm{u}$ obtener la nacionalidad española; $\mathrm{y}$ al inicio inmediato de las acciones pertinentes para entregar a las Naciones Unidas las responsabilidades adquiridas por España como potencia administradora en 1962. Disponible en Migrar con Derechos (Aurelia Álvarez): http://www.migrarconderechos.es/legislationMastertable/legislacion/PNL_Sahara_Izquierda_plural;jsessionid=21B510B37ED5F8C94CA0764FD7D56A59.

${ }^{21}$ El movimiento de lucha de los saharauis por la independencia sigue vivo. El Frente Polisario tiene que llamar la atención de la comunidad internacional con acciones como la del reciente bloqueo de camiones una "ilegal" aduana marroquí en Guerguerat. Marruecos ataca y rompe el fuego. España sigue guardando silencio mientras que Naciones Unidas parece validar la postura marroquí (envío de tropas a la zona de conflicto y violación por la parte marroquí de los acuerdos de alto el fuego). La ruptura del alto el fuego es un hecho grave y Francia, tradicional aliado de Marruecos, así lo ha expresado. En España solo el GP Podemos, en el Parlamento, ha justificado la protesta del Polisario, que califica como "pacífica" y denuncia la "inacción e incapacidad" de la ONU. Bien pudiera el GP Podemos, que cogobierna, pasar a la acción y promover una norma especial para resolver normativamente hablando la cuestión de la nacionalidad española de los saharauis. Sobre la opinión acerca de este conflicto, entre otros la de I. CEMBrero, "El Polisario fracasa en su intento de reactivar el conflicto del Sahara occidental", Diario El Confidencial, 13-11-2020. Disponible en: https:/www.elconfidencial.com/mundo/2020-11-13/el-polisario-fracasaen-su-intento-por-reactivar-el-conflicto-del-sahara-occidental_2832143/. 
condicionado a: si residían en territorio nacional, estar provisto de documentación general española; y si se encontraban fuera de él, estuvieran en posesión del documento nacional de identidad bilingüe expedido por las autoridades españolas, o sean titulares del pasaporte español o estén incluidos en los Registros de las representaciones españolas en el extranjero (Artículo Primero). Al interesado se le otorgaba un plazo de un año a partir de la entrada en vigor del Decreto (de 20/11/1975 a 20/11/1976), para manifestar acogerse a sus previsiones mediante comparecencia ante el Juez encargado del Registro civil del lugar de su residencia, o el Cónsul español de la demarcación correspondiente, aportando la documentación mencionada y manifestando su voluntad de optar por la nacionalidad española.

18. Resulta paradójico, como ha señalado J. SOROETA, que siendo la nacionalidad española la única que poseían como súbditos de un Estado colonial (España) se les "concediera" el derecho de opción debiendo renunciar a otra nacionalidad que ostentasen. El precepto partía de un presupuesto falso, la existencia de otra nacionalidad (marroquí en principio). La realidad y los hechos han demostrado lo contrario. La mayoría de los saharauis se negaron a acogerse a la nacionalidad marroquí. De donde, si la única nacionalidad que poseían era la española qué sentido tiene exigir la renuncia a la nacionalidad española para adquirir por opción la nacionalidad española. Un despropósito solo explicable por ese injustificable desatino que fue el Acuerdo tripartito entre Mauritania, Marruecos y España donde nuestro país hizo efectiva su voluntad de abandonar el territorio del Sahara Occidental, dar por finalizada la tutela y administración que ostentaba y declinar cuantas responsabilidades tuviera con el Sahara y sus habitantes ${ }^{22}$.

19. La consecuencia inmediata de dicho Decreto, pero no la más grave humanitariamente hablando, fue desposeer de la nacionalidad española a los saharauis muchos de los cuales no pudieron siquiera plantearse el ejercicio de la opción no solo por la falta de infraestructura administrativa en los territorios que España abandonó a merced de Marruecos, que les imposibilitó de facto el acceso a los registros para obtener los documentos, sino también porque pasaron a sufrir un horrible conflicto bélico que los empujó a un desplazamiento masivo hacia el desierto de Argelia, siendo esta crisis de refugiados, en palabras de ACNUR, la más larga y prolongada de la historia ${ }^{23}$.

20. La dudosa validez de la aplicación "en el tiempo" de los resultados derivados del RD 2258/1975 (desposesión - privación de la nacionalidad española a los saharauis y la conversión en apátridas) ha sido examinada por la doctrina ${ }^{24}$. En la sentencia objeto de este comentario, la cuestión la aborda la Magistrada Parra Lucán en su Voto particular.

21. Tres son los argumentos que avalan de acuerdo con este Voto la inaplicación del del decreto a la situación de la demandante. Con estos argumentos concluimos este análisis:

22. (1) En primer lugar, el objetivo del RD 2258/1976 era adoptar medidas para llevar a cabo la descolonización del territorio no autónomo del Sahara, salvaguardando los intereses españoles. Así se desprende de su Preámbulo cuando afirma, en este contexto, que España ha puesto término definitivo a su presencia en dicho territorio y a "sus poderes y responsabilidades" en la administración del mismo.

\footnotetext{
${ }^{22}$ Sobre estos acuerdos, C. Ruiz Miguel, "Nacionalidad española de los ciudadanos saharauis: secuela de una descolonización frustrada...", op.cit.

${ }^{23}$ ACNUR. EMERGENCIAS (20/04/2020). “[L]os refugiados saharauis llevan 45 años en situación de desplazamiento. La mayoría de los 173.600 refugiados que viven en los campamentos argelinos de Tinduf no han conocido otra vida. Llevan años esperando una solución para volver a su tierra que, de momento, no llega. Tinduf se compone de cinco campamentos que llevan el nombre de ciudades del Sahara Occidental: Bojador, Dajla, El Aaiún, Auserd y Smara”. Disponible en: https://eacnur.org/es/ actualidad/noticias/emergencias/refugiados-saharauis-campamentos-tinduf.

${ }^{24}$ Entre otros: Con exhaustiva referencia a las resoluciones de la DGRN, J. Pérez Milla, "Travesía hacia la nacionalidad española: oasis o desierto en el Sahara", Revista general de legislación y jurisprudencia, № 3, 2011, pp. 419-440. R. VIÑAS FARRÉ, Evolución de la nacionalidad en España: continuidad y cambios más importantes, Cursos de Derecho internacional Relaciones internacionales de Vitoria-Gasteiz. UPV/EHU, 2009, pp. 312-313.
} 
Sin embargo, el objeto directo de la norma es poner fin a la vinculación de los saharauis con España mediante la declaración de anulación y privación de todo valor a los pasaportes y documentos de identificación personal concedidos por las autoridades españolas a los naturales del Sahara "que no ejercieran la facultad de optar" en los términos del mencionado decreto: un año improrrogable mediante declaración ante el Encargado del Registro civil si se hallaban en España o ante el Cónsul español en la demarcación correspondiente, con exhibición de la documentación española indicada (DF $2^{\mathrm{a}}$ ). Formal y jurídicamente el RD es anómalo: primero, porque el supuesto derecho de opción lo que encubre es una anómala carta de naturaleza al ser dictado por el Ministro de Justicia; segundo, porque no hace referencia a los requisitos comunes para la eficacia de la opción: renuncia a la nacionalidad anterior, juramento de fidelidad al jefe del Estado e inscripción en el Registro civil; y, tercero, porque presuponía una sucesión de Estados que en el caso de el Sahara occidental no ha tenido lugar.

23. (2) En segundo lugar, el RD 2258/1976 puso fin a "la asimilación" de los saharauis llevada a cabo durante la etapa de provincialización. Se les privó de los derechos políticos reconocidos (como el de representación en Cortes o el voto en el referéndum o el acceso como funcionarios a puestos de la Administración española) y se les desposeyó de su nacionalidad al suprimir la validez de su documentación española si no ejercían en el plazo de un año la manifestación de querer ser españoles. Como hemos señalado, el Decreto arbitra un derecho de opción presuponiendo una sucesión de Estados cuando en realidad no hubo tal pues, como hemos indicado, el Acuerdo tripartito (Marruecos, Mauritania y España) se hizo al margen del Derecho internacional ${ }^{25}$.

24. (3) En tercer lugar, el resultado político pretendido por la norma es la privación de la nacionalidad española a quienes eran españoles según las normas vigentes en aquel momento y por la propia realidad, avalada por la política de asimilación seguida por España. Si estamos de acuerdo con esta premisa, es sostenible que la solicitante era española iure sanguinis (entraría en el ámbito del art. 17.a) Cc). Y, por la misma fuerza de razón no es sostenible que perdiera su nacionalidad española por aplicación del mencionado decreto dado que, de acuerdo con la legislación sobre nacionalidad vigente a la fecha (Ley de 15 de julio de 1954), para que se produjera la pérdida era preciso o la adquisición voluntaria de otra nacionalidad o la pérdida por sanción o la pérdida de la nacionalidad española de la mujer casada con extranjero (pérdida basada en el principio de unidad familiar y privilegio del varón). Vista la pérdida de la nacionalidad española a la luz de la normativa constitucional actual, entender que la solicitante perdió la nacionalidad por aplicación del RD 2258/1976 sería contraria a lo dispuesto en el artículo 11.2 CE (ningún español de origen puede ser privado de su nacionalidad).

25. Como reflexión de cierre cabría formular otra hipótesis, ligeramente apuntada en el Voto particular: si la demandante devino apátrida por aplicación del RD 2258/1976 y si esta situación se ha prolongado en el tiempo, ¿es conforme al ordenamiento constitucional vigente y a los compromisos internacionales asumidos por España no subsumir el supuesto de hecho en el ámbito del artículo $17.1 \mathrm{c}$ ) C.c.? - Mantener que los efectos del Real Decreto no se han agotado en el tiempo y pervive su aplicación incluso con la Constitución española en vigor, sería defendible si el resultado (sus efectos) no contradijera nuestros compromisos internacionales de reducir los supuestos de apatridia y la interpretación de dicho resultado fuera conforme con las previsiones del artículo $10.2 \mathrm{CE}^{26}$.

\footnotetext{
${ }^{25}$ United Nation - Treaty Series. Declaración de Principios entre España, Marruecos y Mauritania sobre el Sahara occidental, hecha en Madrid el 14 de noviembre de 1975. Disponible en: https://treaties.un.org/doc/Publication/UNTS/Volume\%20 988/volume-988-I-14450-Other.pdf

${ }^{26}$ Convención sobre el estatuto de los apátridas, hecha en Nueva York el 28 de septiembre de 1954 y Convención para reducir los casos de apatridia, hecha en Nueva York el 30 de agosto de 1961.
} 